\section{AB0317 DO MECHANICAL AND INFLAMMATORY RHEUMATOLOGIC DISEASES LEAD TO THE SAME SLEEP DISORDERS?}

W. Hamdi, M. Boudokhane, I. Cherif, D. Kaffel, K. Maatallah, M. Kchir Rheumatology, Kassab Institute, Tunisia, Tunisia

Background: Sleep disorders are frequent feature of chronic rheumatologic diseases. They are reported in inflammatory diseases as well as in mechanical disorders but they are not systematically assessed by clinicians. It is necessary to identify the frequency and factors associated to sleep problems in order to reduce their impact on patient's quality of life.

Objectives: We aim to describe the sleep pattern in inflammatory and mechanical chronic rheumatologic diseases and to assess factors associated with sleep disorders.

Methods: We conducted a cross-sectional study during 1 year including Tunisian patients with chronic inflammatory rheumatism (rheumatoid arthritis: RA according to the criteria ACR 1987 and axial spondyloarthritis: AS according to modified NEW YORK criteria) and patients with mechanical disorders (chronic low back pain and primitive knee osteoarthritis). Sleep has been evaluated by the MOS-SS questionnary. For each group specific disease parameters were assessed at the same time of the administration of the questionnary.

Results: We collected 120 patients with chronic inflammatory rheumatism (group 1) and 80 patients with mechanical disorder (group2). Group 1 was composed of 70 RA and 50 SPA including 65 women and $55 \mathrm{men}$. The average age was 46.95 [18.75]. Group 2 was composed of 40 chronic low back pain and 40 primitive knee osteoarthritis including 48 women and $32 \mathrm{men}$. The average age was 51.95 [18.82]. Sleep disorders were frequent in both groups, but they were more noticeable in Group 1 patients than Group 2 patients $53.68 \%$ vs $26.38 \%(p=0.00)$. Risk factors for sleep disorders in rheumatoid arthritis were disease activity $(p=0.00)$ and functional impairment $(p=0.00)$. In patients with spondyloarthritis, risk factors for sleep impairment were disease activity (BASDAI $(p=0.00)$, ASDAS vs $(p=0.00)$ et ASDAS CRP $(p=0.00))$ and impaired quality of life $(p=0.00)$. The factors involved in sleep disorders in chronic low back pain was the reduced lumbar spine mobility assessed by the finger-toground distance $(p=0.00)$ and the schober index $(p=0.01)$ and functional impairment assessed by Eiffel questionnaire $(p=0.00)$. In patients with knee osteoarthritis the Lequesne index $(p=0.008)$, the knee extension limitation $(p=0.00)$ and the radiological damage $(p=0.004)$ were associated to sleep impairment.

Conclusions: Our results illustrate the frequency of sleep disorders in chronic rheumatic diseases. They should not be under estimated in patients with mechanical disorders. A better control of the factors associated to sleep impairment for each disease should help promoting a better sleep quality in patients with chronic rheumatologic diseases.

Disclosure of Interest: None declared

DOI: 10.1136/annrheumdis-2018-eular.5736

\section{AB0318 ARE PATIENTS EXPERIENCING DIFFERENT SORT OF FATIGUE DEPENDING ON THE TYPE OF CHRONIC RHEUMATISM?}

W. Hamdi, M. Boudokhane, I. Cherif, D. Kaffel, K. Maatallah, M. Kchir.

Rheumatology, Kassab Institute, Tunisia, Tunisia

Background: Fatigue is frequently reported by patients with inflammatory chronic diseases as well as in mechanical rheumatologic disorders. But it's not recognised and treated as priority by clinicians. It is necessary toidentify the frequency of this symptom and to determinate it's impact on the quality of life of patient.

Objectives: We aimed to assess andto compare the frequency and the intensity of fatiguebetween inflammatory and degenerative chronic rheumatologic diseases, and to identify the factors correlated with fatigue in these diseases.

Methods: We conducted a cross-sectional study during 1 year including Tunisian patients with chronic inflammatory rheumatism (rheumatoid arthritis: RA according to the criteria ACR 1987 and axial spondyloarthritis: AS according to modified NEW YORK criteria)and patients with mechanical disorders (chronic low back pain and primitive knee osteoarthritis). Fatigue was assessed by the chalder questionnaire including physical and mental fatigue.

Results: We collected 120 patients with chronic inflammatory rheumatism (group 1) and 80 patients withmechanical disease (group2). Group 1 was composed of $70 \mathrm{RA}$ and $50 \mathrm{AS}$ including 65 women and 55 men. The average age was 46.95 [18.75]. Group 2 was composed of 40 chronic low back pain and 40 knee osteoarthritis including 48 women and 32 men. The average age was 51.95 [18.82]. Fatigue was more significantly observed in group 1 than in group 2: $8.40 \%$ vs $5.54 \%$ ( $p=0.000)$. Mental and physical fatigue was noted in $2.1 \%$ and $6.25 \%$ in group $1 \%$ and $1.0 \%$ and $4.49 \%$ in group 2 , respectively. The risk factors for fatigue were in theRA thetender and swollen joint count, the DAS 28 and the HAQ. In AS, factors associated to fatigue were the visual scale of pain,

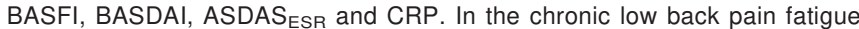
was associated by the functional impairment assessed by the Eiffel questionnaire. Finally knee in osteoarthritis fatigue was associated to Lequesne index and radiological stage.

Conclusions: Fatigue seems to be a frequent symptom in rheumatic diseases and mostly associated to severity and activity of the disease.

Disclosure of Interest: None declared

DOI: 10.1136/annrheumdis-2018-eular.5753

\section{AB0319 MOOD DISORDERS AND CHRONIC RHEUMATOLOGIC DISEASES: ABOUT 200 CASES}

W. Hamdi, M. Boudokhane, I. Cherif, K. Maatallah, D. Kaffel, M. Kchir. Rheumatology, Kassab Institute, Tunisia, Tunisia

Background: Mood disorders are frequently associated to chronic diseases. They are reported in inflammatory diseases as well as in mechanical rheumatologic disorders but they are not systematically recognised and assessed by clinicians. It is necessary to identify the frequency of moods disorders in order to reduce their impact on patient's compliance to treatment.

Objectives: The aim of this study was to assess the impact of chronicrheumatologic diseases on the mood of patients by comparing inflammatory and mechanical diseases and to identify factors correlated with anxiety and depression.

Methods: We conducted a cross-sectional study during 1 year including Tunisian patients with chronic inflammatory rheumatism (rheumatoid arthritis: RA according to the criteria ACR 1987 and axial spondyloarthritis: AS according to modified NEW YORK criteria)and patients with mechanical disorders (chronic low back pain and primitive knee osteoarthritis). Anxiety and depression were assessed by the BAI (Beck anxiety index) and the BDI (Beck depression index), respectively.

Results: We included 120 patients with chronic inflammatory rheumatism (group 1) and 80 patients with mechanical disease (group2). Group 1 was composed of 70 patients with RA and 50 patients with AS including 65 women and 55 men. Their average age was 46.95 [18.75]. Group 2 was composed of 40patients with chronic low back pain and 40 patients with knee osteoarthritis including 48 women and $32 \mathrm{men}$. Their average age was 51.95 [18.82]. Anxiety was significantly more frequent in group 1 than group 2: $15.52 \%$ vs $9.37 \%(p=0.000)$. Depression was significantly more noted in group 1 than group $2: 16.29 \%$ vs $7.16 \%(p=0.009)$. The risk factors for anxiety and depression were respectively in the rheumatoid arthritis:tender and swollen joint count, DAS 28, the HAQ and the sharp erosion score. In AS, factors associated to mood disorders were the visual scale of pain, BASFI, BASDAI, ASDAS ESR and CRP. In the chronic low back pain mood disorders are associated to functional impairment assessed by the Eiffel questionnaire and the reduced mobility of the lumbar spine assessed by the distance finger-soil. Finally knee in osteoarthritis moods disorders were associated to Lequesne index and the reduction of knee extension.

Conclusions: Patients with chronic rheumatologic diseases suffer very often from anxiety and depression which was related in majority of cases to functional impairment, hence the need for multidisciplinary management.

Disclosure of Interest: None declared

DOI: 10.1136/annrheumdis-2018-eular.5776

\section{AB0320 1 IMPACT OF RHEUMATOID ARTHRITIS ON LIFE QUALITY: BEFORE AND AFTER TREATMENT}

X. Grapton ${ }^{1}$, on behalf of CREER, P. Lemesle ${ }^{2}$, on behalf of CREER, L. Arabian ${ }^{3}$, on behalf of CREER, V. Strotz ${ }^{4}$, on behalf of CREER on behalf of CREER. ${ }^{1}$ Private Rheumatology Practice, Colombes; ${ }^{2}$ Private Rheumatology Practice, BoisColombes; ${ }^{3}$ Private Rheumatology Practice, Clamart, ${ }^{4}$ Private Rheumatology Practice, Antony, France

Background: Life quality issues in rheumatoid arthritis (RA) are often spontanously mentioned by patients or identified by rheumatologists. Besides classic follow up parameters like DAS28, we have to consider those issues to improve our patients life quality.

Objectives: Explore and quantify the impact of RA on life quality via everyday's life and psychological items and the effect of treatment on them.

Methods: RA cases were collected by a group of 20 private practice rheumatologists in the Paris area. Basic informations about the patient and his disease were provided by his rheumatologist. Questionnaire including 12 themes and 41 items was filled in by the patient.

Results: 167 cases collected: $82 \%$ women, mean age 57 years, $56 \%$ moderate and $14 \%$ severe disease, 76\% ACPA positive, $73 \%$ structural damage. Initial DAS28 4,7. Post treatment DAS28 2.7. Drugs: classic DMARDs 95\%, corticosteroids $73 \%$, biological DMARDs $22 \%$, combination therapy $76 \%$.

Life quality issues are spontaneously mentioned by $55 \%$ of the patients. 
Before treatment, psychological well-being and housework ability are altered in more than $50 \%$ of the patients. Impact on economy, food and social life occurs in less than $25 \%$ of the cases.

Life quality is mostly altered by pain (85\%), then fatigue $(75 \%)$ and handicap (58\%)

We find a correlation between the severity of RA and the importance of the impact on psychological well-being, sexual life and hobbies.

After treatment, psychological well-being improves in $53 \%$ of the patients, and social life, work, getting about and sexual life in $45 \%-32 \%$.

Items improved around $50 \%$ of the patients are in order: sleep, relation to other people, feeling excluded, social life, depression, sick leave, concentration problems, anxiety and shopping.

We find and improvement in a third of cases in house-keeping, going out, sports and libido.

$72 \%$ of the patients feel a lack of listening by their families, even under treatment Conclusions: Treatment of RA, including drugs and associated measures, reduces the frequency of negative impact on life quality.

We observe that, when DAS28 drops by $43 \%$, the frequency of RA related repercussions diminishes by $31 \%(14 \%-50 \%)$ on the chosen items. All the items are impacted by RA before treatment and stay impacted after treatment, but less frequently, except family relations. More than one patient of 2 gains correct sleep and almost half of them aren't depressed or anxious anymore. Impact on social activity and house-keeping activity are less frequently improved.

Regarding these facts, the rheumatologist has to accomplish a tight follow-up and suggest, besides drug treatment, associated measures like physiotherapy, professionnel activity and environment adaptation and rest among others.

A qualitative evaluation of the improvement will be the subject of a further study. Disclosure of Interest: None declared

DOI: 10.1136/annrheumdis-2018-eular.2274

\section{AB0321 NEGATIVE CORRELATION OF THE ABSOLUTE NUMBER OF CD4 +CD25+FOXP3+REGULATORY T CELLS TO THE LEVELS OF RHEUMATOID FACTOR IN PERIPHERAL BLOOD OF NEW ONSET PATIENTS WITH RHEUMATOID ARTHRITIS}

X. Jianfang ${ }^{1}$, C. Gao ${ }^{2}$, X. Li ${ }^{1}$, G. Liu'. ${ }^{1}$ Second Hospital of Shanxi Medical University, Taiyuan, China; ${ }^{2}$ Pathology, Brigham and Woman's Hospital, Boston, USA

Background: Rheumatoid arthritis (RA) is a progressive immune-mediated disease that can culminate in joint destruction and early mortality. High levels of serum RF are associated with a worse prognosis in RA. The role of is not fully understood. Recently, Our studies have found that the absolute number of peripheral $\mathrm{CD}^{+} \mathrm{CD}^{+} 5^{+} \mathrm{Foxp}^{+}$regulatory $\mathrm{T}\left(\mathrm{CD} 4^{+} \mathrm{Treg}\right)$ cells decreased in RA patients. Interestingly, regulatory $T$ cell epitopes (Tregitopes) in IgG have been reported as the main component of intravenous immunoglobulin therapy (IVIG) and provide one explanation for the expansion and activation of Treg cells following IVlg treatment. We hypothesise that RF joins with IgG to form large molecular complexes, which interrupts the production of Tregitopes in antigen presenting cells as a cause of reduction of $\mathrm{CD} 4^{+}$Treg cells.

Objectives: The aim of this study is to investigate whether the absolute number of $\mathrm{CD} 4^{+}$Treg cells is associated with the titers of auto-antibodies in blood of newonset diagnosed patients with RA.

Methods: A total of 57 new-onset diagnosed patients with RA were enrolled and healthy donors as control. The absolute number of peripheral $\mathrm{CD} 4^{+}$Tregs cells was detected by multicolor flow cytometry combined with an internal microsphere counting standard. 46 of new-onset cases were tested the levels of RF and antiCCP with ELISA method. IIF method was used to detect APF and AKA. Low titers group and high titers group around with the value $1: 80$. All data was analysed by SPSS 22.0.

Results: The absolute number of $\mathrm{CD}^{+}$Treg cells in peripheral blood of newonset patients with RA was significantly lower than in healthy controls [25.1 $(16.01,40.75)$ vs $33.0567(22.9,43.18), p<0.05]$. Interestingly, the reduction of peripheral $C D 4^{+}$Treg cells was negatively correlated to RF titers (correlation coefficient $-0.488, p<0.01$ ) but not to other auto-antibodies against CCP, APF and AKA. The absolute number of $\mathrm{CD} 4^{+}$Tregs in high titers RF group was lower than in low titers RF group $[20.5(14.0,40.0$ vs $34.0(29.7,44.6), p<0.05]$. There was statistically significant difference in two titers groups.
Abstract AB0321 - Table 1. Spearman correlation analysis of absolute number of CD4 ${ }^{+}$ Treg cells and autoantibodies titers in 46 new-onset RA patients

\begin{tabular}{lllll}
\hline & RF & AKA & APF & a- \\
& & & & CCP \\
\hline $\begin{array}{l}\text { CD4 } \\
+ \text { Treg }\end{array}$ & $-0.488^{* *}$ & -0.126 & -0.328 & 0.104
\end{tabular}

+ Treg

${ }^{* *} \mathrm{p}<0.01$

Abstract AB0321 - Table 2. The absolute number of CD4+Treg cells Contrast with different titers group

\begin{tabular}{lcccc}
\hline RF & $n$ & $M\left(P_{25}, P_{75}\right)$ & $Z$ & $P$ \\
\hline Low titer & 13 & 34.0 & -2.127 & 0.033 \\
group & & $(29.7,44.6)$ & & \\
High titer & 33 & 20.5 & & \\
group & & $(14.0,40.0)$ & & \\
\hline
\end{tabular}

A

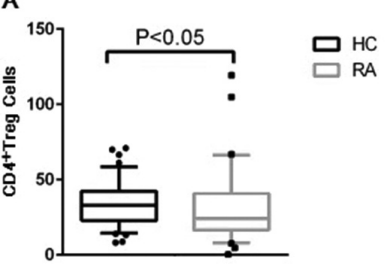

B

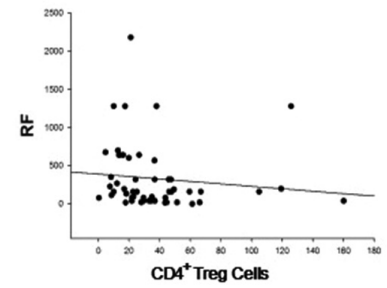

c

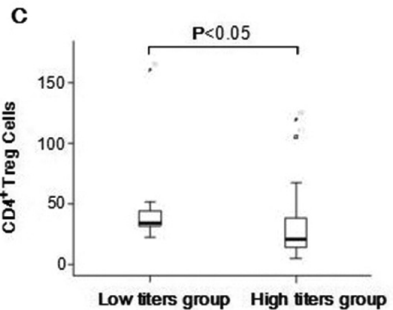

Abstract AB0321 - Figure 1. The absolute number of $\mathrm{CD}^{+}{ }^{+}$Treg cells were reduced in peripheral blood of the all enrolled new-onset RA patients $(n=57)(A)$. The reduction of peripheral $\mathrm{CD} 4^{+}$Treg cells from new-onset patients were negatively correlated with the levels of RF tested in these subjects (B). There was statistically significant difference in two titers groups of RF (C).

Conclusions: The absolute number of CD4 ${ }^{+}$Treg cells in peripheral blood of new-onset patients with RA was significantly decreased compared with that in health controls. Furthermore, the reduction of peripheral CD4 ${ }^{+}$Treg cells was negatively correlated to the titers of $\mathrm{RF}$, suggesting that $\mathrm{RF}$ contributes to the reduction of CD4 + Tregs cells. The correlation of decreased CD4 ${ }^{+}$Treg and RF may be involved in the pathogenesis of poor prognosis in RA.

\section{REFERENCE:}

[1] Cousens LP, Najafian N, Mingozzi F, Elyaman W, Mazer B, Moise L, Messitt TJ, Su Y, Sayegh M, High K, Khoury SJ, Scott DW, De Groot AS. In vitro and in vivo studies of IgG-derived Treg epitopes (Tregitopes): a promising new tool for tolerance induction and treatment of autoimmunity. J Clin Immunol 2013 Jan;33(Suppl 1):S43-9. doi:10.1007/s10875-012-9762-4 [Epub 2012 Sep 2. Review].

Disclosure of Interest: None declared DOI: 10.1136/annrheumdis-2018-eular.4959 